\title{
Psoriasis Causes Significant Economic Burden to Patients
}

\author{
A. Mustonen $\cdot$ K. Mattila $\cdot$ M. Leino $\cdot$ L. Koulu $\cdot$ R. Tuominen
}

To view enhanced content go to www.dermtherapy-open.com

Received: March 28, 2014 / Published online: May 28, 2014

(c) The Author(s) 2014. This article is published with open access at Springerlink.com

\section{ABSTRACT}

Introduction: Psoriasis results in expenses to patients from many cost sources. Psoriasis treatments may result in considerable time and traveling costs, yet many studies fail to account for these costs. The objective of this study was to evaluate the multidimensional economic burden of psoriasis to patients.

Methods: The study was based on 232 Finnish patients with psoriasis or psoriatic arthritis visiting a tertiary level dermatological clinic during a 1-year study period between October 1, 2009 and September 30, 2010. The data were

Electronic supplementary material The online version of this article (doi:10.1007/s13555-014-0053-2) contains supplementary material, which is available to authorized users.

A. Mustonen $(\bowtie) \cdot$ K. Mattila $\cdot$ M. Leino $\cdot$ L. Koulu Department of Dermatology, Turku University Hospital and University of Turku,

Lemminkäisenkatu 1, 20014 University of Turku, Turku, Finland

e-mail: atmust@utu.fi

R. Tuominen

Department of Public Health, University of Turku and Primary Health Care Unit, Hospital District of Southwest Finland, Turku, Finland based on a patient questionnaire, clinical data from the medical records and reimbursement data from the Finnish Social Insurance Institution. Item costs were based on true costs charged from the patients and all time cost estimates were based on the Human Capital Approach method.

Results: 199 patients with psoriasis and 33 with psoriatic arthritis were included in the study. Total costs were higher for patients receiving traditional systemic medications or phototherapy than those not receiving such treatment. Travel costs and travel time costs accounted for more than $60 \%$ of the costs of phototherapy. Skin care at home was time consuming and thus caused significant burden to patients. The majority of the visit costs arose from hospital visits and only a small proportion were attributed to visiting primary health care providers.

Conclusion: Visit charges and other patient copayments were estimated to play a minor role in the total cost of psoriasis incurred by patients, while travel costs and lost time comprised the majority of the costs, which should not be omitted in future studies regarding costs of treatments. 
Keywords: Cost; Dermatology; Patient; Phototherapy; Psoriasis; Psoriatic arthritis; Travel costs

\section{INTRODUCTION}

Psoriasis is a common chronic inflammatory disease with a prevalence of $1.5-2.8 \%$ worldwide [1, 2]. Around $6-30 \%$ of patients with psoriasis also have psoriatic arthritis [3-5]. Psoriasis is a lifelong disease thus leading to considerable burden and expenses $[1,6]$. When assessing the health economic consequences of a disease, the perspective of patients is considered important [1, 7].

Psoriasis results in expenses to patients from many cost sources mainly because of medications, topical emollients and balneotherapy [8-12]. Some psoriasis treatments (mainly phototherapy) are given in hospitals, usually in as a course of treatment, so considerable time and traveling costs can be expected $[7,11,13]$. Studies have estimated that patients have to spend a lot of time each day in home care of psoriasis, but the results have wide variations [11, 12]. Psoriasis also increases the need for cleaning and laundry, and increases the need for assistance at home [11].

Psoriasis has no known curative treatment; therapy aims to reduce symptoms and gain quality of life. Topical steroids and vitamin D analogs are shown to be the most commonly used treatment method [5]. Phototherapy and/ or systemic medications are combined if necessary [5]. Countries have varying social/ private insurance systems, thus the costs of medications for the patients varies.

The aim of this study was to evaluate the multidimensional economic burden of psoriasis to patients.

\section{MATERIALS AND METHODS}

\section{Patient Sample}

The sample was based on patients who had visited the Department of Dermatology in Turku University Hospital (TUH) between October 1, 2009 and September 30, 2010. They were all diagnosed with moderate to severe psoriasis or psoriatic arthritis. The patient sample is described in detail by Mattila et al. [14]. In the Finnish healthcare system patients with mild psoriasis are treated in primary health care settings and only moderate to severe cases are referred to tertiary level hospitals for further treatment. In practice, all psoriatic arthritis patients in this study sample also had skin symptoms, which had been the reason for visiting a dermatological clinic.

\section{Ethical Consideration}

The ethical committee of The Hospital District of Southwest Finland approved the study. The patients received a written description of the sampling procedure and study purpose, as well as the planned use and storage of the information they were to provide. This was followed by a description of the subject's rights according to the Helsinki declaration. All procedures followed were in accordance with the ethical standards of the responsible committee on human experimentation (institutional and national) and with the Helsinki Declaration of 1975, as revised in 2000 and 2008. Written informed consent was obtained from all patients for use of their medical records being included in the study. 


\section{Questionnaire}

The questionnaire collected socio-demographic background information (e.g., sex, age, home municipality, number of persons living in the same household, income level and disease duration).

To evaluate the use of different medical services and associated out-of-pocket expenses and time spent, the subjects were asked the number of visits they had made to a private or occupational health care provider, to a tertiary level hospital and to a health center because of psoriasis during the study period of 1 year. The visits to doctors' office and nurse in each health care facility were recorded separately. The time spent, in hours per year, was recorded for each health service provider. The subjects were asked to evaluate the out-of-pocket expenses associated with the different health care providers. The subjects were also asked to estimate the distances to each health care provider in kilometers from their home.

The subjects were asked to report how many minutes per week they currently spend on caring for their skin, cleaning and laundry, and to estimate the time in minutes per week they would have spent in a hypothetical situation if they did not have psoriasis. Skin care, cleaning and laundry time caused by psoriasis was defined as the difference between estimated time spent in skin care, cleaning and laundry with and without psoriasis.

The subjects were asked if they received any assistance with running errands or household chores because of psoriasis and respective costs (in euro per month).

\section{Time Cost}

All cost estimates were computed to hours per year. To estimate the monetary value of the burden from the time consumed for household chores, running errands, for skin care and treatment-related time, the Human Capital Approach (HCA) was used. The value of an hour was based on the level of total family income per persons in the household. The monthly income levels were computed to an hour. The same formula was applied to retired and unemployed respondents.

\section{Clinical Data}

Clinical information was collected from the medical records for the time period that was covered in the questionnaire data. Outpatient and phototherapy visits and the days hospitalized were collected from the hospital records.

Psoriasis area severity index (PASI) and diagnosis [ICD-1010 (International Statistical Classification of Diseases and Related Health Problems)] were collected to classify the severity and the type of psoriasis. If there were many PASI values from the same patient, the mean value for the study period was calculated and used in the analyses.

Patients were divided into subgroups for further assessment by type of psoriasis (psoriatic arthritis and psoriasis) and the severity of psoriasis according to PASI values. When analyzing the subgroups with recorded PASI values $(n=72)$ patients were divided by the median value into more severe (PASI $>5.5$, $n=37$ ) and less severe psoriasis (PASI $\leq 5.5$, $n=35)$. Patients were categorized to those who received phototherapy and those who did not, and to those who were receiving traditional systemic medications (including methotrexate, acitretin, and cyclosporine) and to those who did not (receiving mainly phototherapy and/or topical therapy). Patients may be included in more than one group, as combined therapy was possible. 


\section{Pharmaceuticals}

In practice, Finnish patients with psoriasis receive reimbursements for all their medications and emollients from the Finnish Social Insurance Institution (FSII). FSII provided data on all psoriasis-related medication including different drugs (biologic, systemic and topical), supportive drugs (e.g., antifungal drugs and antihistamines) and self-care products (e.g., emollients) purchased during the study period for the patients who had given consent. This reimbursement policy applies to all medications, irrespective of who has prescribed them. All purchase data included the cost for the patient and the amount reimbursed as well as the type of medication purchased. If the out-of-pocket expenses for medicine and emollients exceed 672 euro during a calendar year, the exceeding reimbursement was at a rate of $100 \%$ so the cost maximum was set to 672 euro.

\section{Travel Costs and Time}

Travel costs were estimated using the distances from patients' home to different health care providers and the number of visits in each destination. If the distance to a service provider was less than $12.5 \mathrm{~km}$, a typical regional bus fee of 2.5 euro was applied. For distances beyond $12.5 \mathrm{~km}, \quad 0.20$ euro $/ \mathrm{km}$ derived from FSII reimbursement rate for traveling cost was used for costs calculations.

The time patients spent on traveling to different health service providers was estimated using the distance to the service provider from their home municipality and the number of visits to each provider; register data were used for TUH visits. An approximation of $1.5 \mathrm{~min}$ per kilometer was used with an additional fixed amount of $5 \mathrm{~min}$ representing the time needed to park the car or walk from the bus stop to the hospital. In the few cases where the estimated travel time to a service provider and back home exceeded $2.5 \mathrm{~h}$, it was capped at $2.5 \mathrm{~h}$.

\section{Visit Time}

The time spent at different health care providers was solicited in the questionnaire and used to evaluate the costs of the time needed for visits. Due to the significance of time needed for phototherapy, a separate survey was conducted, where the actual time needed by 40 patients with psoriasis attending phototherapy at TUH was observed. UVB and bath-PUVA therapies were separately recorded. UVB visits took on average $16 \mathrm{~min}$ and bath-PUVA took $43 \mathrm{~min}$. Other forms of PUVA treatment than bathPUVA were not used. These times were then used for time-cost calculations of phototherapy.

\section{Visiting Charges}

The charge for an outpatient visit to a tertiary level hospital in 2009 was 27.40 euro. For a course of treatment (e.g., phototherapy) the charge was 7.00 euro per visit. For appointments that were missed without prior cancelation, there was a charge of 33.80 euro on each occasion. For inpatient treatment, the daily charge to the patient was 32.50 euro. The combined inpatient and outpatient fees for a patient to a tertiary level hospital were capped at 633 euro during a year, as beyond this level, further visits to hospital are free of charge to the patient. TUH charges were based on register data.

A visit to a private specialist was valued at 100 euro per visit and a visit to a private nurse was valued at 50 per visit. These approximate 
costs were derived from the average charges of the largest private health service providers. FSII reimbursed 20.25 euro for a visit to a private specialist and an average of 8 euro for a visit to a private nurse. These reimbursements were deducted from the average charges to compute the cost to a patient of visiting the private sector. For visiting the health center the charge for the patient is 12.80 euro, which is only claimed for the first three visits. Patients did not pay a visiting fee when visiting a public health sector nurse or an occupational health care provider.

\section{Statistical Analyses}

The statistical evaluation of the data was based on Student's $t$ test for means and Chi-square test for proportions. Linear regression models were used to study how different background factors affected the variation in treatment cost estimates. In the analyses all patients with missing information in any of the analyzed variables were excluded. All analyses were based on all patients irrespective of the diagnosis of psoriasis or psoriatic arthritis.

\section{RESULTS}

The patients had relatively low psoriasis severity (Table 1). The total costs to patients were higher for those receiving traditional systemic medications than not receiving systemic medications (Table 2). Medicine costs, skin care cost and costs of assistance for household chores comprised most of the differences (Table 2). Visit costs were higher for patients not receiving traditional systemic medications, mainly because their costs of phototherapy (217 euro, SD 358) were higher $(p<0.001)$ than for those who received systemic medications (82 euro, SD 228).

Medications and phototherapy formed 18\% of the total economic burden for a patient.

Table 1 Patient characteristics in patients receiving systemic medications, not receiving systemic medications and all patients

\begin{tabular}{llll}
\hline & $\begin{array}{l}\text { Receiving systemic } \\
\text { medications }(\boldsymbol{n}=\mathbf{8 5})\end{array}$ & $\begin{array}{l}\text { Not receiving systemic } \\
\text { medications }(\boldsymbol{n}=\mathbf{1 4 7})\end{array}$ & $\begin{array}{l}\text { All patients } \\
(\boldsymbol{n}=\mathbf{2 3 2})\end{array}$ \\
\hline Mean age (years) & $62(12)$ & $55^{*}(13)$ & $57(13)$ \\
Male & $53 \%$ & $56 \%$ & $54 \%$ \\
PsA patients & $15 \%$ & $12 \%$ & $14 \%$ \\
Mean PASI $(\mathrm{n}=72)$ & $6.3(2.3)$ & $6.6(4.7)$ & $6.5(4.0)$ \\
Mean DLQI $(\mathrm{n}=36)$ & $10.1(8.6)$ & $12.8(7.8)$ & $11.0(8.3)$ \\
Number of total visits & $6(7)$ & $10^{*}(10)$ & $8(9)$ \\
Visit time $(\mathrm{h})$ & $8(29)$ & $8(19)$ & $8(23)$ \\
Travel time $(\mathrm{h})$ & $6(9)$ & $10^{*}(13)$ & $8(12)$ \\
Travel distance $(\mathrm{km})$ & $124(231)$ & $186(329)$ & $163(298)$ \\
Skin care time $(\mathrm{h})$ & $100(126)$ & $76(92)$ & $85(106)$ \\
\hline
\end{tabular}

Described as average or mean annual values (standard deviation in parenthesis)

$D L Q I$ dermatology life quality index, PASI psoriasis area severity index

${ }^{*} p<0.05$, otherwise non-significant 
Table 2 Average annual costs (euro) (standard deviation in parenthesis) for patients, receiving traditional systemic medications (methotrexate, acitretin, cyclosporine), not receiving traditional systemic medications and to all patients

\begin{tabular}{lccc}
\hline Cost item & $\begin{array}{l}\text { Receiving traditional systemic } \\
\text { medications }(\boldsymbol{n}=\mathbf{8 5})\end{array}$ & $\begin{array}{l}\text { Not receiving traditional } \\
\text { systemic medications }(\boldsymbol{n}=\mathbf{1 4 7})\end{array}$ & $\begin{array}{l}\text { All patients } \\
(\boldsymbol{n}=\mathbf{2 3 2})\end{array}$ \\
\hline Medicine + emollients & $286(199)$ & $142^{* *}(186)$ & $194(202)$ \\
Visits to health care providers ${ }^{\mathrm{a}}$ & $343(574)$ & $417(467)$ & $390(509)$ \\
Time spent on skin care & $1,199(1,560)$ & $807^{*}(1,160)$ & $950(1,330)$ \\
Time spent on cleaning + laundry & $281(743)$ & $332(935)$ & $313(869)$ \\
Assistance time & $420(932)$ & $225^{*}(653)$ & $296(771)$ \\
Total & $2,530(2,361)$ & $1,924^{*}(1,981)$ & $2,145(2,142)$ \\
\hline${ }^{* *} p<0.001,{ }^{*} p<0.05$, otherwise non-significant & & \\
${ }^{a}$ Includes all cost items of visits: charges, travel, travel time and visit time &
\end{tabular}

Table 3 The composition of phototherapy costs (euro) (standard deviation in parenthesis) $(n=83)$

\begin{tabular}{lc}
\hline Cost items & Cost \\
\hline Travel costs & $119(151)$ \\
Travel time costs & $181(212)$ \\
Treatment time costs & $66(47)$ \\
Treatment charges & $104(50)$ \\
Total phototherapy cost & $471(387)$ \\
\hline
\end{tabular}

Phototherapy and biologic medications (527 euro, SD 280, $n=14$ ) were the costliest therapies for a patient to receive. Travel costs and travel time costs comprised over $60 \%$ of the costs of phototherapy (Table 3). Patients receiving phototherapy lived on average $10 \mathrm{~km}$ closer to TUH than those who did not receive phototherapy $(p<0.05)$.

A majority of the total visit costs incurred by patients were from visiting TUH and only a small proportion from visiting all primary health care providers (Table 4). Patients with psoriatic arthritis received more phototherapy and had more visits, thus had higher visiting costs than patients with psoriasis (Table 4). Patients with more severe psoriasis (PASI $>5.5$ ) had higher $(p<0.05)$ total visiting costs $(673$ euro, SD 848) than patients with less severe psoriasis $\quad(P A S I \leq 5.5) \quad(359$ euro, SD 369). Patients who received phototherapy had higher $(p<0.001)$ total visiting costs $(673$ euro, SD 658) than the patients who did not receive phototherapy (234 euro, SD 310).

Skin care time (Table 1) was estimated to correspond to almost half of the total economic burden to the patient (Table 2). Patients receiving traditional systemic medications had higher costs for skin care than those who did not (Table 2). Sex, age, diagnosis, the severity of psoriasis or receiving phototherapy did not have a statistically significant effect on skin care costs. A quarter of the study group received assistance for household chores because of psoriasis. For the patients who received assistance, the estimated annual cost was 1,014 euro (SD 1,131).

\section{DISCUSSION}

There is little information concerning the costs of psoriasis incurred by patients. In this study, the co-payments for visits to hospital and for medications and emollients comprised only a minority of the total costs for a patient, while 
Table 4 Average annual costs (euro) of health care visits according to diagnosis (standard deviation in parenthesis)

\begin{tabular}{|c|c|c|c|c|c|}
\hline & \multicolumn{2}{|c|}{ Tertiary level } & \multicolumn{2}{|c|}{ Primary level } & \multirow{2}{*}{$\begin{array}{l}\text { Total visit costs } \\
\text { All patients } \\
(n=232)\end{array}$} \\
\hline & $\begin{array}{l}\text { Psoriasis } \\
(n=199)\end{array}$ & $\begin{array}{l}\text { Psoriasis arthritis } \\
(n=33)\end{array}$ & $\begin{array}{l}\text { Psoriasis } \\
(n=199)\end{array}$ & $\begin{array}{l}\text { Psoriatic arthritis } \\
(n=33)\end{array}$ & \\
\hline Travel costs & $49(96)$ & $125^{* * *}(191)$ & $5(11)$ & $8(18)$ & 65 (119) \\
\hline Travel time cost & $77(151)$ & $178^{* *}(250)$ & $11(33)$ & $16(49)$ & $103(182)$ \\
\hline Visit time cost & $83(296)$ & $127(301)$ & $16(44)$ & $16(25)$ & $105(300)$ \\
\hline Charges & $81(90)$ & $112(121)$ & $28(88)$ & $42(76)$ & $116(120)$ \\
\hline Total costs & $291(466)$ & $543 *(578)$ & $61(139)$ & $82(144)$ & $390(509)$ \\
\hline
\end{tabular}

${ }^{* * *} p<0.001,{ }^{* *} p<0.005,{ }^{*} p<0.05$, otherwise non-significant

travel costs and lost time were estimated to contribute the majority of the costs to patients. In a recent study in Spain [15], the relationship of travel costs and time costs were similar from the patients' perspective.

Phototherapy has been estimated to be costly for patients $[2,7,8,11]$. In this study, biologic therapy and phototherapy had almost equal costs to patients. In studies in the US, lower out-of-pocket costs for patients have been estimated to have led to favoring biologic therapies over phototherapy $[16,17]$. This can lead to higher total costs for the society of psoriasis treatment as phototherapy has been estimated to be the most cost-efficient, or one of the most cost-efficient, treatment methods of psoriasis [18-20]. However, travel costs and travel time costs are rarely included in cost estimations of psoriasis treatments [16, 19-21], which may have led to underestimation of the actual costs of phototherapy. The current sample included all patients visiting the clinic during 1 year. Thus, all types of phototherapy patients can be assumed to be represented, those in remission as well as those in active treatment; and the costs were based on the actual number of visits during the whole year.

In this study the indirect costs were estimated to comprise the majority of costs of phototherapy for the patients. Earlier studies have estimated that travel costs account for around two-thirds of the total costs of phototherapy [22]. Time lost because of phototherapy has been estimated to be around $110 \mathrm{~min} /$ treatment session [22] or take $33 \mathrm{~h}$ per year [11]. It has been reported that, from the perspective of patients, travel distance plays a major role in treatment selection [23]. Loss of time, whether working or leisure time, has value to the patients, irrespective of the lost earnings. In this study, the aim was to analyze the burden of the disease to a patient, not to employers, or the society as a whole. Thus, possible productivity losses from absenteeism or presenteeism were not included.

A recent study suggests that patients living further away from UV-treatment facility have lower dermatology life quality index (DLQI) and suffer from lack of treatment [23]. The current study indicated that patients living further away from tertiary level hospital receive less phototherapy, which may be due, in part, to the decisions made by patients and not just the decisions made by treatment providers. Studies are required to determine if patients living further away from service provider suffer from under treatment. Home phototherapy is rarely used in our study area 
although it seems that, at least for patients living further away from the service provider, it could increase treatment options.

In some earlier studies [16], medication costs were estimated using average prices and average weekly doses. This can be a source for potential overestimates of medication costs as a considerable proportion of psoriasis patients do not necessarily use the medications as prescribed [24]. In the study all medicine and emollient costs were based on reimbursement data of all purchases, irrespective of who had prescribed the medications, which can be expected to produce more reliable medication cost estimates. Countries have varying social security systems and reimbursement rates so direct comparison between studies has been considered problematic [7, 12, 25]. For example, in this study setting, the cut-off level for complete medicine cost reimbursement was based on national policy. Thus, the medication costs to patients in this study may not be directly generalizable to other countries.

As in this study, earlier studies [8, 19] have shown that patients receiving systemic medications and/or phototherapy have higher costs than those who were receiving only topical treatment. Patients with systemic medication or phototherapy also have been estimated to have lower quality of life and a higher likelihood of treatment failure than other patients [19, 26]. In some studies, patients receiving systemic medication or phototherapy have been classified as having severe psoriasis no matter what PASI scores they had $[11,13]$. On the other hand, patients receiving systemic treatment or phototherapy have been found to have lower PASI values than other patients [8], possibly due to successful control of psoriasis in patients receiving adequate treatment. In the authors' previous work [27] topical therapies were most often combined with other forms of treatment. More severe psoriasis patients, who receive systemic medications to control their symptoms, may need more extensive self-care than those who manage with less care, irrespective of PASI values. These issues could explain why, in this study, almost all costs were higher for patients using systemic medications or phototherapy even though the severity of psoriasis was almost the same. However, in our study only 72 patients had PASI values in their medical records, so analyses with PASI values are not as generalizable as other results and should be treated with more caution.

The primary provider of treatment for patients with psoriasis varies between countries [28]. In most studies patients have been treated mainly by dermatologists [28, 29], as in this study. In Finland, patients with well managed and mild psoriasis are usually treated by general practitioners, with referral to a tertiary level dermatological clinic when exacerbations occur. This may have led to selection bias in the sample as only patients from the dermatological clinic were included.

The current study corroborates earlier studies $[8,11,13,30]$ that time devoted to skin care, household chores and assistance for household chores imposes a considerable burden to patients with psoriasis. The estimates for time used for skin care/topical treatment in previous studies, have had a wide range from $4 \mathrm{~min} /$ daily [11] to $57.5 \mathrm{~min}$ daily [8]. In this study, the use of two different questions regarding skin careone estimating the time needed for skin care due to psoriasis and one for the hypothetical time needed for skin care if the patient did not have psoriasis, may have produced more reliable results on time needed due to psoriasis. The study suggests that the time devoted to skin care is a considerable burden, contributing to almost half of the total costs for the patient. Laundry 
and cleaning seemed to have minor role in costs for the patient, with the majority of patients reporting negligible impact of psoriasis. For those needing assistance, it may form a considerable cost burden.

\section{CONCLUSION}

Information concerning the costs of psoriasis from the perspective of patients is still limited. In this study, the co-payments for visits to hospital and for treatments were estimated to play a minor role in the total costs for a patient, with travel costs and lost time contributing most of the costs. These indirect costs of treatments should not be omitted in future studies as they can be a significant factor when choosing treatments, especially for the patients with psoriasis.

\section{ACKNOWLEDGMENTS}

All named authors meet the ICMJE criteria for authorship for this manuscript, take responsibility for the integrity of the work as a whole, and have given final approval for the version to be published.

This study and associated article processing charges were supported by grants from the Hospital District of Southwest Finland.

Conflict of interest. A Mustonen, K. Mattila, M. Leino, L. Koulu and R. Tuominen declare that they have no conflict of interest.

Compliance with ethics. The ethical committee of The Hospital District of Southwest Finland approved the study. The patients received a written description of the sampling procedure and study purpose, as well as the planned use and storage of the information they were to provide. This was followed by a description of the subject's rights according to the Helsinki declaration. All procedures followed were in accordance with the ethical standards of the responsible committee on human experimentation (institutional and national) and with the Helsinki Declaration of 1975 , as revised in 2000 and 2008. Written informed consent was obtained from all patients for use of their medical records being included in the study.

Open Access. This article is distributed under the terms of the Creative Commons Attribution Noncommercial License which permits any noncommercial use, distribution, and reproduction in any medium, provided the original author(s) and the source are credited.

\section{REFERENCES}

1. Radtke MA, Augustin M. Economic considerations in psoriasis management. Clin Dermatol. 2008;26(5):424-31.

2. Raychaudhuri SP, Farber EM. The prevalence of psoriasis in the world. J Eur Acad Dermatol Venereol. 2001;15(1):16-7.

3. Gelfand JM, Gladman DD, Mease PJ, et al. Epidemiology of psoriatic arthritis in the population of the United States. J Am Acad Dermatol. 2005;53(4):573.

4. Kaipiainen-Seppanen O. Incidence of psoriatic arthritis in Finland. Br J Rheumatol. 1996;35(12): 1289-91.

5. Lambert J, Dowlatshahi EA, de la Brassinne M, Nijsten T. A descriptive study of psoriasis characteristics, severity and impact among 3,269 patients: results of a Belgian cross sectional study (BELPSO). Eur J Dermatol. 2012;22(2):231-7.

6. Nijsten T, Looman CW, Stern RS. Clinical severity of psoriasis in last 20 years of PUVA study. Arch Dermatol. 2007;143(9):1113-21.

7. Raho G, Koleva DM, Garattini L, Naldi L. The burden of moderate to severe psoriasis: an overview. Pharmacoeconomics. 2012;30(11):1005-13. 
8. Sohn S, Schoeffski O, Prinz J, et al. Cost of moderate to severe plaque psoriasis in Germany: a multicenter cost-of-illness study. Dermatology. 2006;212(2):137-44.

9. Navarini AA, Laffitte E, Conrad C, et al. Estimation of cost-of-illness in patients with psoriasis in Switzerland. Swiss Med Wkly. 2010;140(5-6):85-91.

10. Berger K, Ehlken B, Kugland B, Augustin M. Cost-ofillness in patients with moderate and severe chronic psoriasis vulgaris in Germany. J Dtsch Dermatol Ges. 2005;3(7):511-8.

11. Meyer N, Paul C, Feneron D, et al. Psoriasis: an epidemiological evaluation of disease burden in 590 patients. J Eur Acad Dermatol Venereol. 2010;24(9):1075-82.

12. Schoffski O, Augustin M, Prinz J, et al. Costs and quality of life in patients with moderate to severe plaque-type psoriasis in Germany: a multi-center study. J Dtsch Dermatol Ges. 2007;5(3):209-18.

13. Ghatnekar O, Ljungberg A, Wirestrand LE, Svensson A. Costs and quality of life for psoriatic patients at different degrees of severity in southern Sweden-a cross-sectional study. Eur J Dermatol. 2012;22(2):238-45.

14. Mattila K, Leino M, Mustonen A, Koulu L, Tuominen R. Influence of psoriasis on work. Eur J Dermatol. 2013;23(2):208-11.

15. Ruano J, Isla-Tejera B, Jimenez-Puya R, RodriguezMartin A, Cardenas M, Gomez F, et al. Long-term cost-effectiveness analysis of etanercept and adalimumab for plaque psoriasis not associated with arthritis. Dermatol Ther (Heidelb). 2013;3(2):131-42.

16. Miller DW, Feldman SR. Cost-effectiveness of moderate-to-severe psoriasis treatment. Expert Opin Pharmacother. 2006;7(2):157-67.

17. Yentzer BA, Feldman SR. Trends in home phototherapy adoption in the US: monetary disincentives are only the tip of the iceberg. J Dermatol Treat. 2011;22(1):27-30.

18. Hankin CS, Feldman SR, Szczotka A, et al. A cost comparison of treatments of moderate to severe psoriasis. Drug Benefit Trends. 2005;17:200-14.

19. Pearce DJ, Nelson AA, Fleischer AB, Balkrishnan R, Feldman SR. The cost-effectiveness and cost of treatment failures associated with systemic psoriasis therapies. J Dermatol Treat. 2006; 17(1):29-37.

20. Feldman SR, Garton R, Averett W, Balkrishnan R, Vallee J. Strategy to manage the treatment of severe psoriasis: considerations of efficacy, safety and cost. Expert Opin Pharmacother. 2003;4(9):1525-33.

21. Anis AH, Bansback N, Sizto S, Gupta SR, Willian MK, Feldman SR. Economic evaluation of biologic therapies for the treatment of moderate to severe psoriasis in the United States. J Dermatol Treat. 2011;22(2):65-74.

22. de Rie MA, de Hoop D, Jonsson L, Bakkers EJ, Sorensen M. Pharmacoeconomic evaluation of calcipotriol (Daivonex/Dovonex) and UVB phototherapy in the treatment of psoriasis: a Markov model for The Netherlands. Dermatology. 2001;202(1):38-43.

23. Uttjek M, Dufaker M, Nygren L, Stenberg B. Determinants of quality of life in a psoriasis population in northern Sweden. Acta Derm Venereol. 2004;84(1):37-43.

24. Storm A, Andersen SE, Benfeldt E, Serup J. One in 3 prescriptions are never redeemed: primary nonadherence in an outpatient clinic. J Am Acad Dermatol. 2008;59(1):27-33.

25. Carrascosa JM, Pujol R, Dauden E, et al. A prospective evaluation of the cost of psoriasis in Spain (EPIDERMA project: phase II). J Eur Acad Dermatol Venereol. 2006;20(7):840-5.

26. Feldman SR, Evans C, Russell MW. Systemic treatment for moderate to severe psoriasis: estimates of failure rates and direct medical costs in a north-eastern US managed care plan. J Dermatol Treat. 2005;16(1):37-42.

27. Mustonen A, Mattila K, Leino M, Koulu L, Tuominen R. The costs of psoriasis medications. Dermatol Ther (Heidelb). 2013;3(2):169-77.

28. Fouere S, Adjadj L, Pawin H. How patients experience psoriasis: results from a European survey. J Eur Acad Dermatol Venereol. 2005;19(Suppl 3):2-6.

29. Wong JW, Davis SA, Feldman SR, Koo JY. Trends in older adult psoriasis outpatient health care practices in the United States. J Drugs Dermatol. 2012;11(8):957-62.

30. Vender R, Lynde C, Ho V, Chau D, Poulin-Costello M. Work productivity and healthcare resource utilization outcomes for patients on etanercept for moderate-to-severe plaque psoriasis: results from a 1-year, multicentre, open-label, single-arm study in a clinical setting. Appl Health Econ Health Policy. 2012;10(5):343-53. 